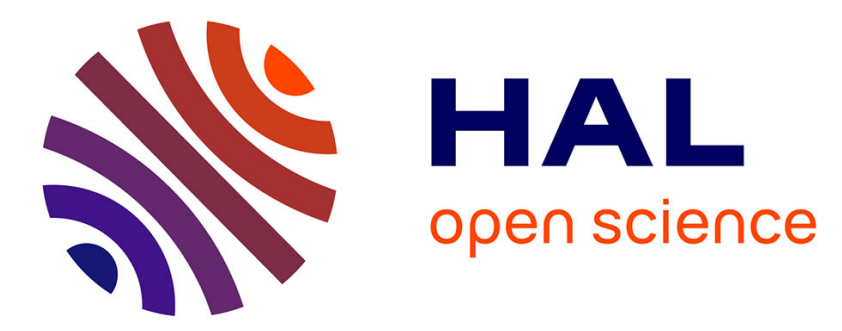

\title{
INFLUENCE OF LOADING RATE ON ANISOTROPY OF COMPACT BONE
}

\author{
Y. Tanabe, S. Tanaka, M. Sakamoto, T. Hara, H. Takahashi, Y. Koga
}

\section{To cite this version:}

Y. Tanabe, S. Tanaka, M. Sakamoto, T. Hara, H. Takahashi, et al.. INFLUENCE OF LOADING RATE ON ANISOTROPY OF COMPACT BONE. Journal de Physique IV Proceedings, 1991, 01 (C3), pp.C3-305-C3-310. 10.1051/jp4:1991343 . jpa-00250486

\section{HAL Id: jpa-00250486 https://hal.science/jpa-00250486}

Submitted on 1 Jan 1991

HAL is a multi-disciplinary open access archive for the deposit and dissemination of scientific research documents, whether they are published or not. The documents may come from teaching and research institutions in France or abroad, or from public or private research centers.
L'archive ouverte pluridisciplinaire HAL, est destinée au dépôt et à la diffusion de documents scientifiques de niveau recherche, publiés ou non, émanant des établissements d'enseignement et de recherche français ou étrangers, des laboratoires publics ou privés. 


\title{
INFLUENCE OF LOADING RATE ON ANISOTROPY OF COMPACT BONE
}

\author{
Y. TANABE* ${ }^{*}$ S. TANAKA*, M. SAKAMOTO**, T. HARA*, H. TAKAHASHI** \\ and Y. KOGA** \\ * Department of Mechanical Engineering, Faculty of \\ Englneering, Niigata University, Ikarash1 2-nocho, Nilgata \\ 950-21, Japan \\ * Nifgata Technical Junior College, Kamishin'ei-cho 5-13-7. \\ Niigata 950-21, Japan \\ * *Department of Orthopedic Surgery. School of Medicine, \\ Nigata University, Asahimachidori 1-bancho, Niigata 951. \\ Japan
}

\begin{abstract}
Résumé : Le comportement dynamique en compression d'os de fémur de bovin (os plexiforme) est étudié par la technique des barres de Hopkinson (S.H.P.B.). Une méthode est developpee pour identifier les caractéristiques viscoélastiques de l'os à partir de la réponse transitoire fournie par les essais. Cette méthode et le problème transitoire associé sont rapidement présentés. La transformation de Laplace et un shéma d'itération de type "GaussNewton" sont utilisés. Le caractère anisotrope des propriétés viscoélastiques de l'os est ainsi mis en évidence. L'influence de la vitesse de chargement sur l'anisotropie du module élastique de l'os est étudiée cn comparant les résultats des essais dynamiques aux résultats d'essais quasi-statiques et de mesures par méthode ultrasosnore réalisés dans une précédente étude.
\end{abstract}

\begin{abstract}
Impact compression experiments for bovine femoral compact bone (plexiform bone) are performed using the split-Hopkinson pressure-bar (SHPB) technique. A method is developed for the identification of the viscoelastic characteristics of the bone using transient response information arising from the SHPB tests. The solution procedures of the identification problem and that of the associated stress wave propagation problem are briefly shown. They are accomplished by means of application of the method of the Laplace transformation and a Gauss-Newton iterative scheme. The orientational dependence of the viscoelastic properties of the bone is examined using the method established, and the influence of loading rate on the oricntational dependence of the elastic modulus of the bone is investigated by comparing the results of the impact compression experiments by the SHPB with those of quasi-static compression experiments and ultrasonic measurements obtained in our previous study.
\end{abstract}

\section{1.-Introduction.}

In order to reveal the mechanism of the fracture or damage of bone tissue,biomechanical approach concerning the mechanical properties of it under various loading rates is indispensable. Many researches on the orientational dependence of the elastic modulus of compact bone in terms of quasi-static experiments[1] or ultrasonic technique[2] have been reported; however,limited work on the anisotropic behaviour of the bone under high rates of compressive strain has been performed[3].

The objectives of this study are:

1. To determine viscoelastic characteristics of fresh bovine femoral compact bone under impact compression as a function of the orientation using the split-Hopkinson pressure-bar (SHPB) technique.

2. To reveal the influence of loading rate (or strain rate) on the orientational dependence of the elastic modulus of the same bone comparing results of impact compression experiments by the SHPB with those of quasi-static compression tests and ultrasonic measurements obtained in our previous papaer [4]. 


\section{2.-Method for estimating the viscoelastic characteristics of the bone from experi- mental information of the SHPB tests.}

A brief description of the method for the identification of the viscoelastic properties of the bone is presented in this chapter.

It is known that the mechanical behaviour of the bone agrees well wi.th that of the three-element standard linear solid according to the theory of poroelasticity[5]. We then consider longitudinal stress wave propagation in the SHPB with a smalI viscoelastic cylindrical specimen which is initially quiescent and whose mechanical behaviour is represented by the model as shown in Fig.l and constitutive equation is ziven by Eq.(1):

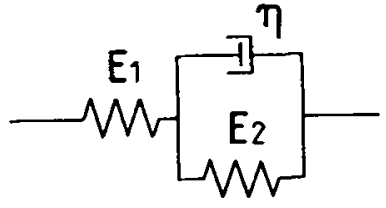

Fig.1.-Three-element standard linear solid. $(\rho, S)$

Specimen

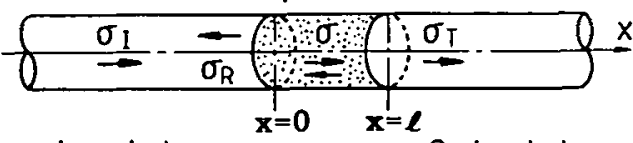

\section{Input bar \\ $\left(\rho_{0}, B_{0}, S_{0}\right)$}

Fig.2. -Wave propagation in the splitHopkinson pressure-bar with a viscoelastic specimen.

$$
\sigma+\frac{\eta}{E_{1}+E_{2}} \frac{\partial \sigma}{\partial t}=\frac{E_{1} E_{2}}{E_{1}+E_{2}} \varepsilon+\frac{E_{1} \eta}{E_{1}+E_{2}} \frac{\partial \varepsilon}{\partial t}
$$

where $\sigma$ and $\varepsilon$ denote the longitudinal stress and strain, respectively,t the time, $E_{1}$ and $E_{2}$ the stiffnesses of the springs, $n$ is the viscosity coefficient of the dashpot. On referring to Fig.2, basic equations which govern the longitudinal wave propagation phenomenon in the SHPB are given as follows:

$$
\begin{array}{ll}
\frac{\partial \sigma}{\partial x}=\rho \frac{\partial v}{\partial t} & ; x=0 \\
v=\frac{c_{0}}{E_{0}}\left(\sigma_{R}-\sigma_{I}\right) & ; x=0 \\
\sigma=\frac{S_{0}}{S}\left(\sigma_{R}+\sigma_{I}\right) & ; x=\ell \\
v=-\frac{c_{0}}{E_{0}} \sigma_{T} & ; x=\ell \\
\sigma=\frac{S_{0}}{S} \sigma_{T} &
\end{array}
$$

where $\sigma_{T}, \sigma_{R}$ and $\sigma_{T}$ denote incident,reflected and transmitter stress wave, respective$1 \mathrm{y}, \mathrm{v}$ the particle velocity, $x$ the longitudinal spatial coordinate. $\rho, l$ and $S$ denote the density,the length and the cross-sectional area of the specimen,respectively while $\rho_{0}, E_{0}$ and $S_{0}$ are the density, Young's modulus and the cross-sectional area of the input-output bars, respectively. $c_{0}=\sqrt{E_{0} / \rho_{0}}$ is the elastic wave velocity in the input and output bars. Now suppose that transmitter stress history is measured at a station on the output bar,designated $\sigma_{m}(t)$. The problem we wish to solve is:Based on this stress measurement, to identify parameters $P=\left(E_{1}, E_{2}, n\right)$ in $E q .(1)$, and to predict stress history at the same station of the output bar. This problem can be reduced to the identification one which is to find the best $P$ so that the least squares distance function attains its minimum value; in other words, since the theoretical transmitter stress wave, designated $\sigma_{\mathrm{T}}=g(t ; P)$, is defined by the solution of Eqs.(1)-(6) which depends on parameters $P$, the problem can be explicitly stated as 


$$
\min _{P} F=\min _{P}\left(\sum_{k=1}^{N}\left[g\left(t_{k} ; P\right)-\sigma_{m}\left(t_{k}\right)\right]^{2}\right)
$$

where $t_{k}(k=1,2, \cdots, N)$ is a discrete time point, $F=\sum_{k=1}^{N}\left[g\left(t_{k} ; P\right)-\sigma_{m}\left(t_{k}\right)\right]^{2}$ the least squares distance function. Using a Gauss-Newton iterative scheme with damping factor[6],the minimization problem ( 7 ) can be successfully carried out. Convergence is taken to be reached if each parameter changes by less than $10^{-2}$ times its value. Analyses to obtain the numerical solutions to Eqs.(1)-(6) are done by using the Laplace transformation and the numerical inversion of it by the use of the fast Fourier transformation (FFT) algorithm. Detailes on the analyses can be found in the previous work[7].

\section{3.-Experiment.}

A series of experiments with the SHPB was conducted to determine the viscoelastic properties of the bone using the method previously described.

\section{1.-Experimental system.}

The arrangement of the SHPB apparatus used in this work is shown in Fig.3. The impact velocity of the striker bar was selected to be about $1.3 \mathrm{~m} / \mathrm{s}$ so that the maximum strain rate of about $100 / \mathrm{s}$ was obtained. The incident and transmitter stress wave profiles were detected by the foil strain gages, $1 \mathrm{~mm}$ in length, mounted on the input and output bars. Each profile of the stress pulses was recorded and stored in a digital storage oscilloscope. Subsequent operations of the recorded data were performed in a personal computer. Prior to inserting a specimen into the apparatus, each

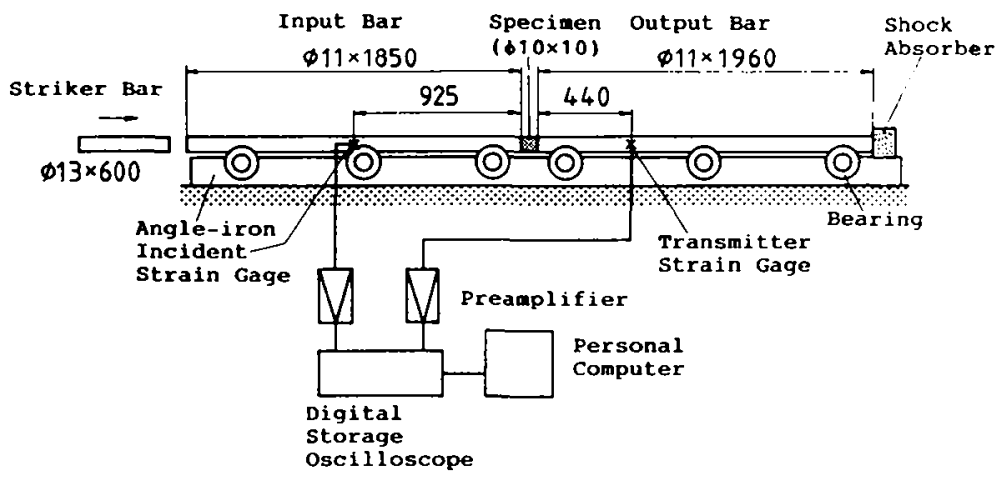

Fig.3.-Split-Hopkinson pressure-bar apparatus.

end face of the specimen was coated with a lubricant to reduce the frictional forces and,at the same time,ensure contact at the interfaces to permit stress wave transmission. All tests were done at room temperature $\left(20^{\circ} \mathrm{C}\right)$.

\section{2.-Specimen preparation.}

All specimens were fabricated from batches of fresh frozen femur bone taken from cattle at the average age of seven or eight months. Each bone sample was machined from the cortex of the anterior part of the femoral mid-diaphysis into a cylindrical specimen with $10 \mathrm{~mm}$ in diameter and $10 \mathrm{~mm}$ in length. The Cartesian coordinate system was assumed in the cortical bone to define the orientation of the specimen as shown in Fig.4. The Bone axis was parallel to the long axis of the bone. The Tangential axis was the tangential direction while the Radial axis was the endosteal-periosteal direction. These axes were specified by eye and denoted BA,TA and RA, respectively. Specimens were cut with their long axis in the BA-direction,TA-direction and RAdirection. Off-axis specimens were also prepared with their long axis in the BATA plane,BA-RA plane and TA-RA plane at angles of $15^{\circ}, 30^{\circ}, 45^{\circ}, 60^{\circ}, 75^{\circ}$ to the BA, TA and RA, respectively. After sectioning, specimens were stored in saline solution at $5^{\circ} \mathrm{C}$ 


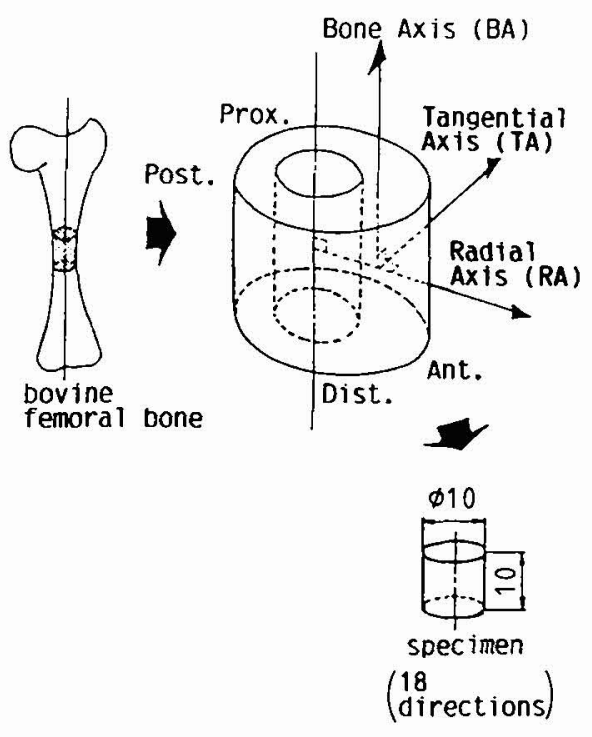

Fig.4.-Cartesian coordinate system chosen for cortical bone specimens.

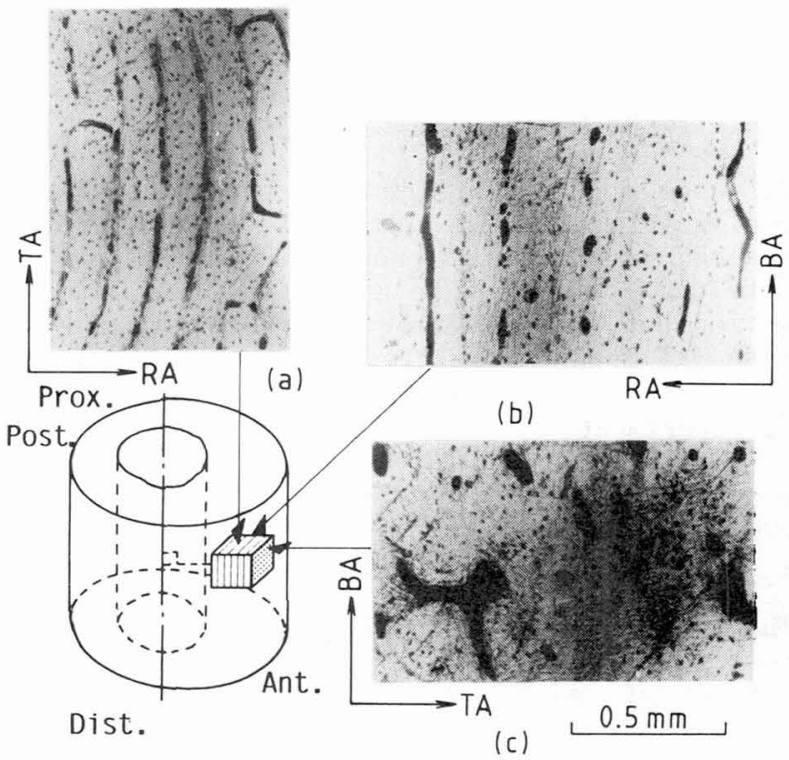

Fig. 5.-Microstructures of bone samples observed at (a)BA-, (b)TA- and (c)RAsurfaces.

and tested within $12 \mathrm{hr}$. Figures $5(\mathrm{a}),(\mathrm{b})$ and (c) show the typical optical micrographs of the surface of bone samples perpendicular to the BA, TA and RA, respectively. Specimens tested in this study were plexiform, and lacking Haversian bone. Three specimens were tested for each orientation.

\section{3.-Results of the characterization of the viscoelastic properties of the bone.}

The transmitter stress wave profile for the specimen oriented to the BA-direction measured on the output bar and the corresponding predictions of the stress histories are shown in Fig.6. The parameter values at different stages of iteration are also given in the same figure. Initial parameters were guessed based on experimental data obtained by the conventional analysis of the SHPB technique. As can be seen from Fig.6, the final parameter values yielded fairly good predictions for the transmitter stress wave profile. The similar results were also obtained for specimens oriented to other directions. Thus,Fig. 6 emphasizes that bovine femoral compact bone (plexiform bone) used here can be represented by the three-element standard linear solid model.

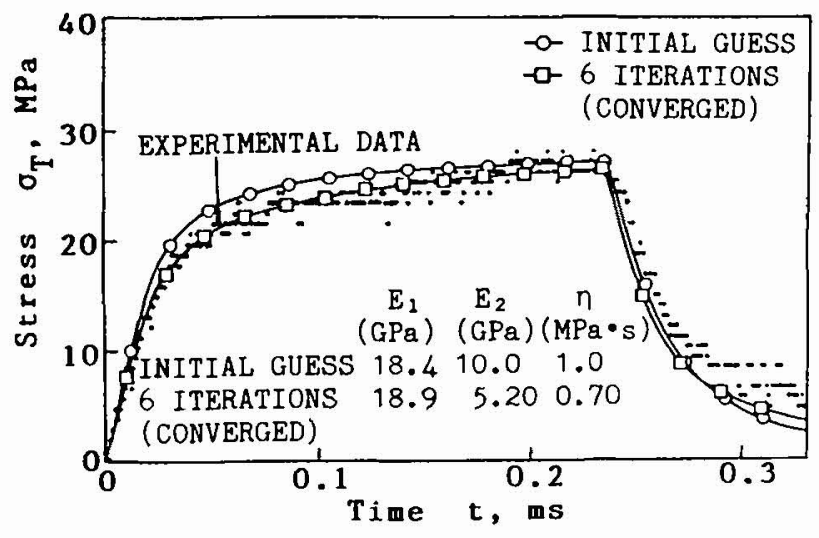

Fig.6.-Pulse prediction at various stages of identification. (Specimen axis oriented to the BA-direction.) 
Figure 7 shows the viscoelastic characteristics of the bone as a function of orientation. The stiffness $E_{1}$ takes a maximum value in the BA-direction while it becomes both minimal and almost constant in the RA-TA plane. The stiffness $E_{2}$ takes an almost constant value of $7 \mathrm{GPa}$ in all directions. The values of the viscosity coefficient $n$ are scattered,but the variation trend of it with the orientation is similar to that of the stiffness $E_{1}$; that is, $n$ tends to be large in directions with high values of $E_{1}$ and small in those with low values of $E_{1}$. From Fig.7,it is found that the rigidity

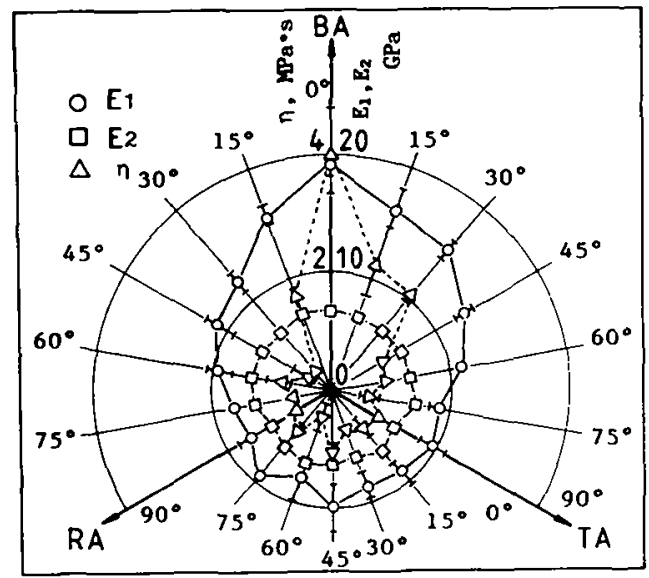

Fig.7.-Variation of viscoelastic characteristics with respect to the orientation of specimen axes.

and the internal friction loss of the bone under impact compression are greatest in the BA-direction; in other words, the function of it as a shock absorber in the BA-direction is superior to that in the other directions.

\section{4.-Orientational dependence of the elastic modulus of the bone under various loading rates.}

The results of the SHPB experiments described in the preceding chapter are compared with those of our previous study[4] involving ultrasonic measurements and quasistatic compression tests.

Figure 8 shows the orientational dependence of ultrasonic modulus Eu which was de-

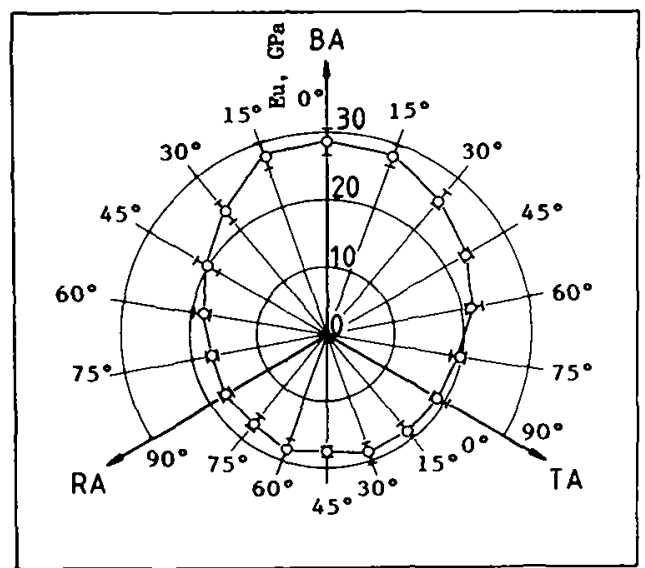

Fig.8.-Elastic modulus by ultrasonic technique as a function of orientation [4].

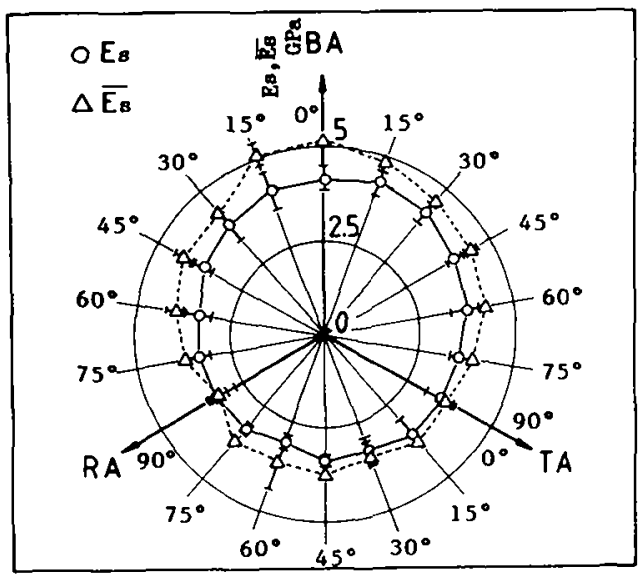

Fig.9.-Elastic modulus under quasistatic compression as a function of orientation [4]. 
rived from the measurement of the velocity of the longitudinal ultrasonic wave in the specimen with a transducer of $5 \mathrm{MHz}$. The ultrasonic modulus $\mathrm{E}_{u}$ is about $1.4 \sim 2$ times as large as the stiffness $E_{1}$ shown in Fig.7 in all directions while the variation trend of $E_{u}$ with the orientation is similar to that of $E_{1}$. The discrepancy between $E_{u}$ and $E_{1}$ is probably due to that in the phase velocity of the wave between these experiments. The ultrasonic wave is the dispersive one, and its propagation velocity (phase velocity) is faster than that of non-dispersive one-dimensional wave travelling down the SHPB.

Figure 9 shows the orientational dependence of the elastic modulus under quasistatic compression at strain rate of about $1.7 \times 10^{-4} / \mathrm{s}$. The quasi-static compressive elastic modulus $E_{S}$ is about one-seventh to one-fifth the size of the ultrasonic one in all directions, and the orientational dependence of it is less evident than that of the ultrasonic modulus. Thus, the orientational dependence of the elastic modulus seems to be more significant at higher loading rates. On the other hand, the elastic modulus under quasi-static compression can be estimated from the results of Fig.7, designated $\overline{E_{S}}$, using the relation: $\bar{E}_{S}=E_{1} E_{2} /\left(E_{1}+E_{2}\right)$. Comparing estimated elastic moduli (denoted by " $\triangle$ " on Fig.9) with measured elastic ones, we can find that they have a good agreement in each other in all directions.

From the results of Figs.7,8 and 9, we can conclude that the orientational dependence of the instantaneous modulus, designated the stiffness $E_{1}$ in this study, of the bone is strongly reflected in the anisotropy in mechanical properties of the bone used here. Furthermore, it should be noted that the bone can be regarded as a isotropic material at low loading rate while it has to be treated as a transversely isotropic one at higher loading rates.

\section{5.-Conclusions.}

The results are summarized as follows:

(1) A method for the identification of the viscoelastic characteristics of the bone has been shown using transient response information arising from the split-Hopkinson pressure-bar tests.

(2) The mechanical behaviour of the bone used in this work (plexiform bone of bovine femora) can be represented by the three-element standard linear solid model. Under impact compression, the rigidity and internal friction loss of the bone in the BAdirection are larger than those in other all directions.

(3) The orientational dependence of the elastic modulus becomes more significant at higher loading rates. This is due to the fact that the anisotropy in mechanical properties of the bone is dominated by the anisotropy in the instantaneous modulus of the bone.

Acknowledgements-The partial support of the Iketani Science and Technology Foundation is gratefully acknowledged. The authors wish to thank K.Kobayashi for assistance in these experiments, and M. Yamada (Yamacho Syokuhin Kogyo Co.,Ltd) for assistance in sample preparations.

\section{References}

/1/ REILLY,D.T. and BURSTEIN,A.H., J.Biomech. 8(1975)393

/2/ KATZ,J.L., Nature 283(1980) 106

/3/ TATEISHI, T., SHIRASAKI, Y., KINOSHITA, Y. and TATEISHI, K., Trans.Jpn.Soc.Mech.Eng. Ser.A 46(1980)438 (in Japanese)

14/ TANABE,Y., TANAKA, S., SAKAMOTO,M. and HARA, T., Proc.34th Jpn. Cong.Mat. Res. (in press)

/5/ NOWINSKI,J.L., AIAA J. 9(1971)62

/6/ LEVENBERG, K., Q.Appl.Math. 2(1944)164

/7/ TANABE, Y., TANAKA,S., SAKaMOTO,M. and HARA, T., Proc.40th Jpn. Cong. Appl.Mech. (to be submitted) 